\title{
THE EFFECTIVENESS OF HYPERBARIC OXYGEN THERAPY ON THE HEALING OF DIABETIC FOOT ULCER: A SYSTEMATIC REVIEW
}

\author{
Heni Selvia
}

Universitas Hasanudin, Indonesia

\begin{abstract}
Background: Foot ulcer is one of the complications that causes major problems in the world for diabetics. If the wound on the foot is not treated immediately, it will lead to complications and the risk of amputation of the extremity. Thus, a strategy is needed in the prevention and treatment of diabetic foot ulcers. Hyperbaric oxygen therapy is hypothesized to affect the wound healing process, reduce exudate, lower inflammatory response, and the risk of amputation. This study aimed to systematically review the relevant research of hyperbaric oxygen therapy to accelerate the healing of diabetic foot ulcer.

Subjects and Method: This was a systematic review using PRISMA Flow Diagram guidelines. The articles published in PubMed, Science Direct, ProQuest, and the Cochrane Library databases, from 2011 to 2021. The study population was patients with diabetic foot ulcer. Intervention was hyperbaric oxygen therapy. Comparison was non hyperbaric oxygen therapy. Outcome was endothelial growth factor serum. The inclusion criteria were randomized controlled trial and full-text in English. The eligible articles were assessed qualitatively.

Results: A total of 7 randomized control trials from Egypt, Australia, Taiwan, India, Indonesia, and Malaysia was included in this study. Endothelial growth factor serum was high in the hyperbaric oxygen therapy group compared to the control group.

Conclusion: Hyperbaric oxygen therapy has benefit on the wound healing process in patients with diabetic foot ulcer.
\end{abstract}

Keywords: diabetic foot ulcer, hyperbaric oxygen therapy, wound healing process.

\section{Correspondence:}

Hey Selvia. Universitas Hasanuddin, Indonesia. Jl. Pioneer of Independence, Makassar City. Email heniselvia.unhas22@gmail.com. Mobile: +6282291738049. 